\title{
Intestinal adherence associated with type IV pili of enterohemorrhagic Escherichia coli O157:H7
}

\author{
Juan Xicohtencatl-Cortes, ${ }^{1}$ Valério Monteiro-Neto, ${ }^{1,2}$ Maria A. Ledesma, ${ }^{1}$ Dianna M. Jordan, ${ }^{3}$ \\ Olivera Francetic, ${ }^{4}$ James B. Kaper, ${ }^{5}$ José Luis Puente, ${ }^{6}$ and Jorge A. Girón ${ }^{1}$ \\ ${ }^{1}$ Department of Immunobiology, University of Arizona, Tucson, Arizona, USA. ${ }^{2}$ Centro de Ciências da Saúde, \\ Centro Universitário do Maranhão, São Luís, Maranhão, Brazil. ${ }^{3}$ Department of Veterinary Diagnostic and Production Animal Medicine, \\ College of Veterinary Medicine, lowa State University, Ames, lowa, USA. ${ }^{4}$ Unité de Genetique Moleculaire, CNRS URA 2172, Institut Pasteur, \\ Paris, France. ${ }^{5}$ Center for Vaccine Development, University of Maryland School of Medicine, Baltimore, Maryland, USA. \\ ${ }^{6}$ Departamento de Microbiología Molecular, Instituto de Biotecnología, Universidad Nacional Autónoma de México, Cuernavaca Morelos, Mexico.
}

\begin{abstract}
Enterohemorrhagic Escherichia coli (EHEC) O157:H7 causes hemorrhagic colitis and hemolytic uremic syndrome (HUS) by colonizing the gut mucosa and producing Shiga toxins (Stx). The only factor clearly demonstrated to play a role in EHEC adherence to intestinal epithelial cells is intimin, which binds host cell integrins and nucleolin, as well as a receptor (Tir) that it injects into the host cell. Here we report that EHEC 0157:H7 produces adhesive type IV pili, which we term hemorrhagic coli pilus (HCP), composed of a 19-kDa pilin subunit (HcpA) that is encoded by the $h c p A$ chromosomal gene. HCP were observed as bundles of fibers greater than $10 \mu \mathrm{m}$ in length that formed physical bridges between bacteria adhering to human and bovine host cells. Sera of HUS patients, but not healthy individuals, recognized HcpA, suggesting that the pili are produced in vivo during EHEC infections. Inactivation of the $b c p A$ gene in EHEC EDL933 resulted in significantly reduced adherence to cultured human intestinal and bovine renal epithelial cells and to porcine and bovine gut explants. An $e s c N$ mutant, which is unable to translocate Tir, adhered less than the $h c p A$ mutant, suggesting that adherence mediated by intimin-Tir interactions is a prelude to HCP-mediated adherence. An $b c p A$ and stx1,2 triple mutant and an $b c p A$ mutant had similar levels of adherence to bovine and human epithelial cells while a stx1,2 double mutant had only a minor defect in adherence, indicating that HCP-mediated adherence and cytotoxicity are independent events. Our data establish that EHEC 0157:H7 HCP are intestinal colonization factors that are likely to contribute to the pathogenic potential of this food-borne pathogen.
\end{abstract}

\section{Introduction}

Since its first description in the early 1980s (1), enterohemorrhagic Escherichia coli (EHEC) of O157:H7 and other serotypes have emerged as a significant cause of serious human gastrointestinal disease worldwide (2-4). EHEC infections can result in diarrhea ranging from mild to bloody and can induce hemorrhagic colitis $(2,5)$, and some patients with hemorrhagic colitis develop a severe complication known as the hemolytic uremic syndrome (HUS). HUS is defined as a triad of clinical features that includes acute renal failure, thrombocytopenia, and microangiopathic hemolytic anemia, which commonly lead to death (6). This deadly infectious disease affects humans of all ages, but the young and old are the most susceptible to developing HUS (7). Adult cattle, other farm animals, and wild animals are common reservoirs of many EHEC serotypes $(8,9)$. Human infection occurs through acquisition of the bacteria via consumption of contaminated food (ground meat or vegetables), water, unpasteurized fruit juices, and milk $(10,11)$.

Nonstandard abbreviations used: AE, attaching and effacing; ECP, Escherichia coli common pilus (pili); EHEC, enterohemorrhagic Escherichia coli; HCP, hemorrhagic coli pilus (pili); HUS, hemolytic uremic syndrome; IFM, immunofluorescence microscopy; LB, Luria-Bertani; LEE, locus for enterocyte effacement; MDBK, Madin-Darby bovine kidney; SEM, scanning electron microscopy; STEC, Shiga-toxigenic E. coli; Stx, Shiga toxin(s); TEM, transmission electron microscopy; TFP, type IV pilus (pili).

Conflict of interest: The authors have declared that no conflict of interest exists. Citation for this article: J. Clin. Invest. 117:3519-3529 (2007). doi:10.1172/JCI30727.
Hallmarks of EHEC pathogenicity are its ability to produce 1 or 2 Shiga toxins (Stx), which are responsible for $\operatorname{HUS}(6,12)$, and to colonize the gut mucosa, which leads to the development of histopathological attaching and effacing (AE) lesions. EHEC strains contain a pathogenicity island called the locus for enterocyte effacement (LEE), which encodes most of the genetic elements required for the production of AE lesions (5). EHEC are a subset of the Shiga-toxigenic E. coli (STEC) pathogroup, which encompasses E. coli strains that produce Stx and that may or not contain the LEE region. Some cases of severe disease, including HUS, are caused by LEE-negative STEC strains (13), indicating that the LEE region is not essential for pathogenesis of HUS and that factors outside the LEE are involved in disease.

Colonization of the intestinal mucosa is central to the establishment of EHEC infection in humans (4). E. coli O157:H7 strains bind in vitro to several cultured cell types (14-16) and in vivo to the gastrointestinal tracts of chickens, gnotobiotic piglets, newborn rabbits, and neonatal calves $(14,17-19)$. In adult cattle, the terminal recto-anal junction is thought to be the primary site of colonization of the bovine gastrointestinal tract (20). Despite efforts to identify putative fimbrial adhesins, the only factor clearly demonstrated to play a role in cell adherence of LEE-positive strains is intimin, an outer membrane protein adhesin that mediates intimate bacterial attachment via recognition of its own injected receptor (Tir) or via recognition of host cell integrin or nucleolin $(14,21-24)$. Nonetheless, intimin mutants are still able to colonize 

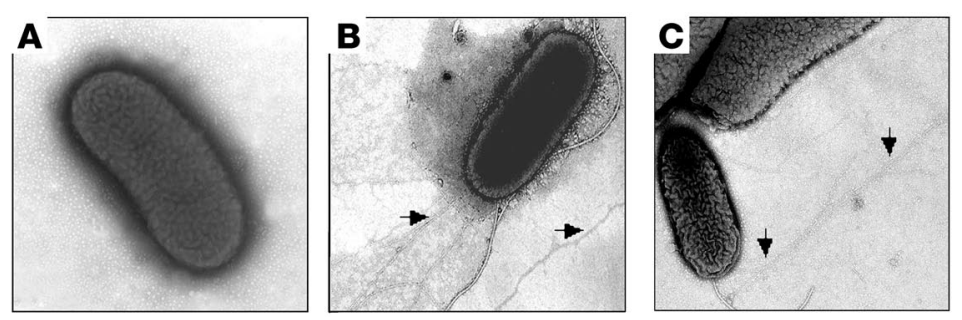

Figure 1

Electron microscopy of EHEC O157:H7 strains. (A) EDL933 grown in LB at $37^{\circ} \mathrm{C}$ shows no pili; (B) EDL933 and (C) $85-170$ show long fine pili (arrows) protruding from the bacteria after growth on Minca agar at $37^{\circ} \mathrm{C}$. The strains were negatively stained and observed by TEM. Original magnification, $\times 20,000$.

host epithelial cells, suggesting that the bacteria produce other yet-unidentified adhesins. Other, less well-characterized surface proteins have been proposed to be associated with adherence properties $(13,15,16,25)$. However, some of these putative adhesins are found only in certain STEC strains, and more studies are required to clarify their role in cell adherence.

The genome of E. coli O157:H7 contains 16 loci encoding genes putatively involved in fimbriae or pili biosynthesis (26-28), but it is unknown how many of them are functional in vivo. Several fimbriae have been identified in EHEC strains, including the sorbitolfermenting EHEC O157 fimbriae plasmid-encoded (SFP) (29), 2 loci-encoding long polar fimbriae (30), curli (31), F9 (a type I pilus homolog) (32), and a type IV pilus (TFP) in LEE-negative non-O157: H7 STEC (33). The role of most of these pili in host colonization is unknown. The long polar fimbriae of EHEC O157:H7 appear to play a role in pig and sheep colonization (34). Intriguingly, EHEC mutants in the F9 pilus showed more adherence to epithelial cells than the wild-type strain (32). Recently, we reported that EHEC strains produce an adhesion appendage called E. coli common pilus or ECP, which is also produced by other pathogenic and nonpathogenic E. coli (35). EHEC and normal flora E. coli unable to produce ECP were hampered in their ability to adhere to cultured epithelial cells. Nevertheless, it remains to be elucidated whether pili play a biologically significant role in EHEC colonization of the intestine of their natural bovine or accidental human hosts.
TFP are important virulence factors in many pathogenic Gram-negative bacteria, as they mediate adherence to eukaryotic cells and host colonization and are associated with other phenomena related to pathogenicity, including bacterial aggregation, biofilm formation, DNA binding and uptake, and twitching motility (36-41). So far, TFP have not been observed in AE-producing EHEC O157:H7. In this study, we demonstrate the expression and assembly of TFP in EHEC O157:H7 and provide data showing that these pili are involved in adherence to cultured human colonic epithelial cells and to porcine and bovine intestinal explants and that the pili induce an antibody immune response in HUS patients. These observations contribute to our knowledge of the mechanisms underlying the interaction of EHEC with host cells.

\section{Results}

Visualization of pili structures produced by EHEC 0157:H7. For the last 20 years, attempts to reproducibly express and characterize pili produced by EHEC strains have been unsuccessful. Analysis of the EHEC EDL933's genome sequence reveals 16 loci with potential to encode pili proteins; however, it is still an enigma what role, if any, pili play in host colonization. We were interested in determining whether, in addition to ECP, EHEC O157:H7 could express and produce any additional pili structures when interacting with host cells.

Ultrastructural studies by negative staining and transmission electron microscopy (TEM) were performed to investigate the presence of pili on 3 prototypic, well-characterized EHEC O157: $\mathrm{H} 7$ strains (EDL933, 86-24, and $85-170$ ) cultivated at $37^{\circ} \mathrm{C}$ on bacteriological media such as Luria-Bertani (LB), Mueller-Hinton, CFA agar, or blood agar. No pili were observed on these strains under these growth conditions (Figure 1A and data not shown). These observations indicate that the expression of pili depends on the composition of the growth medium and is under a strict regulatory and environmental control. Since EHEC is a commensal of cattle, we decided to use minimal casein (Minca) medium, as this medium was used in the past to successfully induce expression of fimbriae in bovine enterotoxigenic E. coli (ETEC) (42). After growth at $37^{\circ} \mathrm{C}$ on Minca agar, we were able to see long $(>20 \mu \mathrm{m})$, thin, rodlike pili (Figure 1, B and C) that associated laterally into bundles,

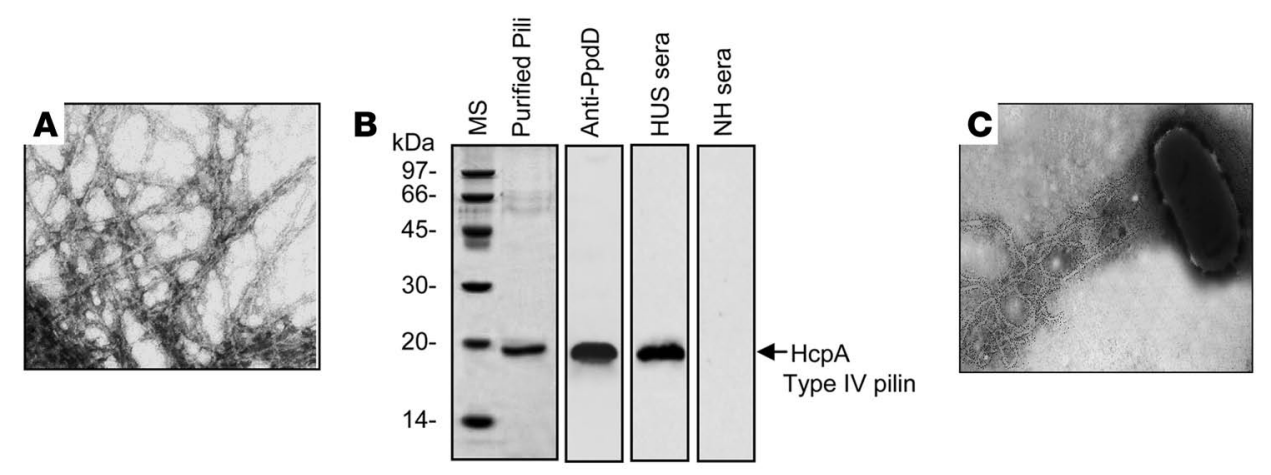

\section{Figure 2}

Purification, biochemical analysis, and reactivity of HCP with sera from HUS patients. (A) TEM micrograph showing bundles of long pili purified from EDL933. (B) Depolymerization of purified pili in 16\% SDS-PAGE gels (MS, mass standards). The 19-kDa protein corresponds to the structural type IV HcpA pilin subunit. The purified pili were reacted with rabbit anti-PpdD $\mathrm{K}_{-12}$ antibody, a pool of human sera from HUS cases, and normal human $(\mathrm{NH})$ sera. Note the reactivity of the pilin subunit with HUS sera and not with $\mathrm{NH}$ sera. (C) Specific immunogold labeling of HCP produced by EHEC EDL933 with anti-HCP antibody. 

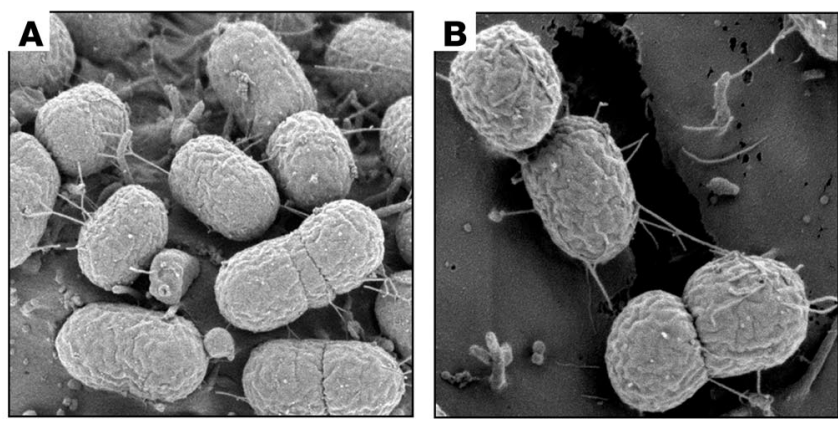

morphologically reminiscent of the ETEC Longus TFP (43). Similar to the production of pili in other E. coli pathogroups $(43,44)$, the degree of production of the novel EHEC pili varied among the 3 EHEC strains tested.

Biochemical characterization of novel pili. To determine the nature of these novel structures, EHEC EDL933 growing on Minca agar at $37^{\circ} \mathrm{C}$ with $5 \% \mathrm{CO}_{2}$ atmosphere was harvested and the pili purified by mechanical shearing and differential centrifugation (45). The purified pili (Figure 2A) were dissociated into pilin monomers of $19 \mathrm{kDa}$ in $16 \%$ SDS-PAGE gels (Figure 2B). This protein was subjected to mass spectrometry analysis after trypsin digestion. The peptides obtained showed amino acid sequences that corresponded to the predicted protein $\mathrm{PpdD}$, which is encoded by the prepilin peptidase-dependent gene ( $p p d D)$ found in the E. coli K-12 genome $(46,47)$. The PpdD protein possesses features of class A type IV pilins, namely, it has a short leader sequence, an invariable glycine residue preceding the leader peptide cleavage site, and a hydrophobic region, which contains an invariable glutamatetyrosine pair of amino acids (48). Previous studies reported that laboratory or pathogenic E. coli strains are not able to assemble the $\mathrm{PpdD}$ protein into a pilus structure (49). The present report is the first, to our knowledge, to demonstrate that EHEC O157:H7 or any other E. coli are indeed able to assemble the PpdD type IV pilin into polar long bundles of laterally aggregated filaments, a typical morphological feature of TFP. Thus, we are proposing the name hemorrhagic coli pilus (HCP) to describe the TFP produced by EHEC O157:H7 that are composed of the HcpA (PpdD) protein encoded by the $h c p A(p p d D)$ gene. Furthermore, the pilin monomer reacted specifically in immunoblots with a rabbit polyclonal antibody against the cloned E. coli K-12 PpdD fused to maltose/ maltodextrin binding protein (Figure $2 \mathrm{~B}$ ). The bundles of HCP protruding from the bacterial cell were labeled by immunogold labeling (Figure $2 \mathrm{C}$ ) with anti-P $\mathrm{PdD}_{\mathrm{K}-12}$ antibodies (herein referred to as anti-HCP), confirming the identity of HCP. No gold particles were seen associated with the bacterial surface, demonstrating the specificity of the reaction.

Organization of the putative HCP operon in EHEC O157:H7. The amino acid sequence of HcpA of EHEC is similar to that of TFP produced by some bacterial pathogens that colonize host tissues, including PilA of Pseudomonas aeruginosa (55\%, GenBank accession number AY113185), PilA of Moraxella catarrbalis (61\%, GenBank accession number AY647185), and PilE of Neisseria gonorrhoeae (62\%, GenBank accession number AF043652). The HcpA of EHEC is highly conserved among the Enterobacteriaceae and shares over 95\% identity with PpdD of E. coli K-12 and Shigella species. The biogenesis of TFP generally requires the function of over 16 genes, often organized in multicistronic operons. It is particularly

\section{Figure 3}

Ultrastructural SEM analysis of EDL933 adhering to HT-29 epithelial cells. (A and $\mathbf{B}$ ) Electron micrographs showing the presence of candle wick-like filamentous structures (arrows) protruding from the bacteria adhering to the mammalian cell surface. These filaments appear to mediate bacteria-to-bacteria interactions and direct contact with the cell surface.

interesting that HCP production in EHEC is apparently driven by the products of fewer genes, namely, $h c p A$ (pilin gene), hofB (usher gene, herein called $h c p B$ ), and $h o f C$ (chaperone gene, herein called $h c p C$ ). These genes are located immediately downstream from $h c p A$ and share similarity to accessory genes pilB and pilC, respectively, involved in the biogenesis of TFP in P. aeruginosa (Supplemental Figure 1; supplemental material available online with this article; doi:10.1172/JCI30727DS1).

Reactivity of HCP with sera from HUS patients. The presence of antibodies in convalescent patients is a biological marker of the production of an antigen in vivo. We sought to determine whether patients who suffered HUS developed antibodies against HCP. A pool of 5 sera from patients with HUS was reacted with purified HCP by Western blotting (Figure 2B). A pool of normal human sera was used as negative control. The $19-\mathrm{kDa}$ pilin subunit was recognized by the HUS sera but not by normal human sera, strongly suggesting that HCP might be produced in vivo during EHEC infection.

Demonstration of HCP on EHEC adhering to host cells. We then investigated the presence of pili-like structures on EHEC bacteria adhering onto cultured HT-29 colonic epithelial cells by highresolution scanning electron microscopy (SEM). We saw that EDL933 attaching to these human intestinal epithelial cells produced wick-like structures (approximately 20-nm wide) protruding from the bacterial surface (Figure 3A). Similar structures were also seen in EHEC adhering to human colonic cell lines (T84 and Caco2), nonintestinal cell lines (HeLa and HEp-2), and bovine kidney (Madin-Darby bovine kidney [MDBK]) epithelial cells (data not shown). These structures appeared to tether bacteria to each other within the bacterial cluster and to mediate direct binding of the bacteria to the mammalian cell membrane (Figure 3B). We hypothesized that these structures could be HCP and so the identity of these structures was investigated by immunofluorescence microscopy (IFM). EDL933-infected HT-29 cells incubated with anti-HCP antibodies revealed the presence of a specific fluorescence profile consistent with the presence of pili (Figure 4A). Similar fluorescent structures were also seen on EHEC incubated with other cell lines (data not shown).

Disruption of hcpA reduces EHEC adherence to epithelial cells. To provide genetic evidence regarding the possible role of HCP in EHEC adherence to epithelial cells, we produced an in-frame deletion in the $h c p A$ gene of EHEC O157:H7 strains EDL933 and 85-170 (Stx-), generating mutants EDL933 $\Delta h c p A$ and 85-170 $\Delta h c p A$ (triple $\Delta s t x 1,2 \Delta h c p A$ mutant), respectively. Flow cytometry, IFM, and Western blotting (of whole bacterial cell extracts) analyses demonstrated the lack of HCP production in these mutants (Figure 4 and Supplemental Figure 2A). No fluorescent structures were seen on the isogenic $h c p A$ mutant with or without $\mathrm{PBAD}-\mathrm{TOPO}$ vector in the presence of epithelial cells (Figure 4, B and E). Infection of HT-29 cells with EDL933 $\triangle h c p A$ complemented with plasmids pJX12 (carrying $h c p A$ ) or pJX22 (carrying $h c p A B C$ ) caused the appearance of an abundant fluorescent meshwork of large bundles of long filaments protruding from the bacteria and extending throughout the obser- 

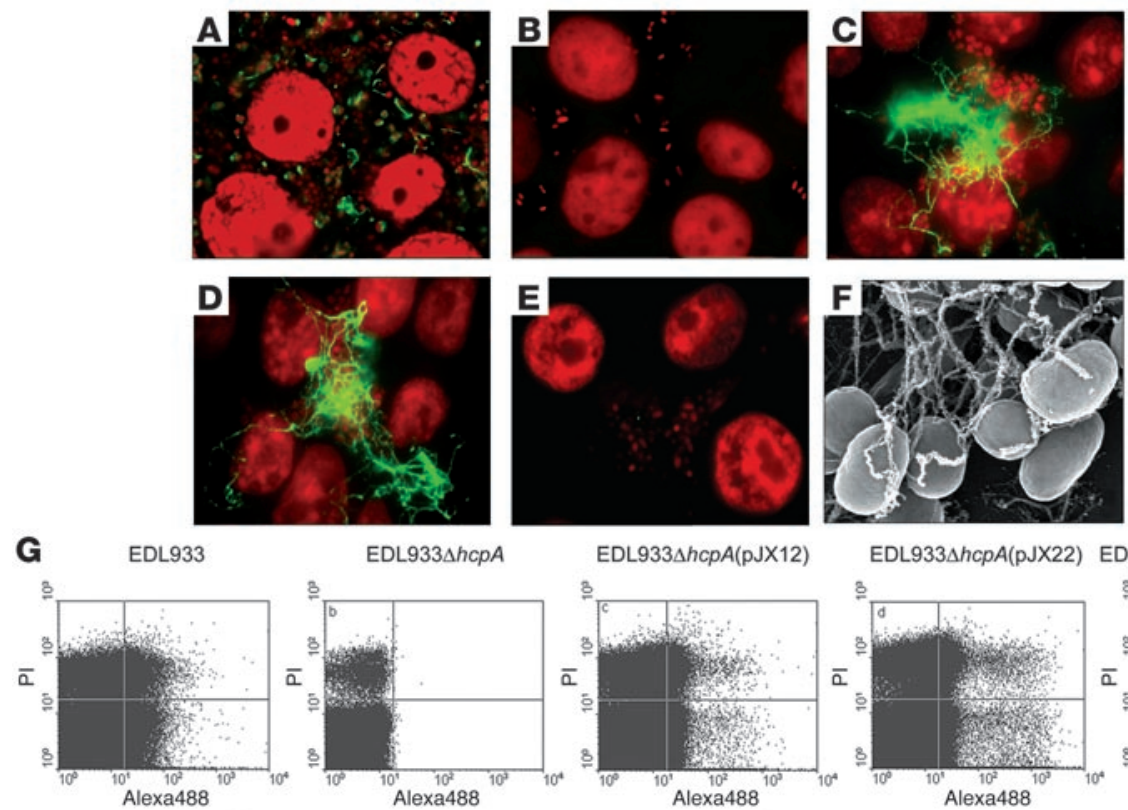

EDL933 $\triangle$ hcpA

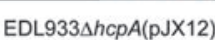

EDL933 $\triangle h c p A($ pJX22) EDL933 $4 h c p A($ pBAD-TOPO)
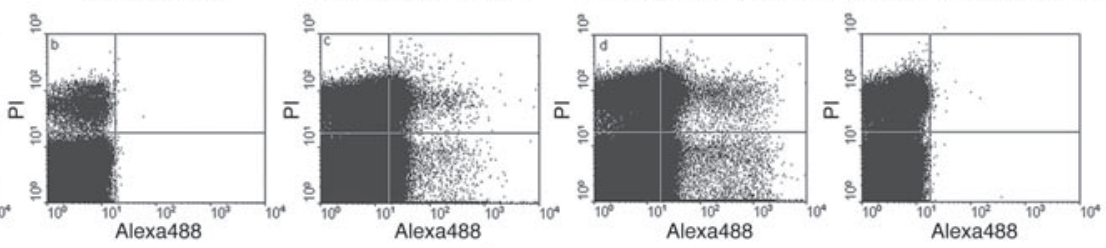

H

I $\mathrm{kDa}$
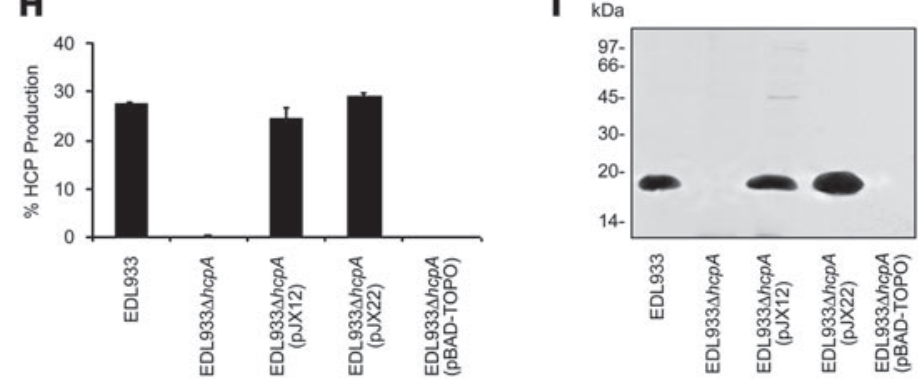

\section{Figure 4}

HCP production in EHEC strains. (A-F) Immunofluorescence of HT-29 cells infected with EHEC strains EDL933 (A), EDL933 $h c p A$ (B), EDL933 $\Delta h c p A(p J X 12)(\mathbf{C})$, EDL933 $\Delta h c p A(p J X 22)(D)$, and EDL933 $\Delta h c p A(p B A D-T O P O)$ (E) using anti-HCP antibody. EDL933 shows short HCP (green), indicated by fluorescent fibers; EDL933 $h c p A(p J X 12)$ and EDL933 $h c p A(p J X 22)$ display extremely long fluorescent filaments that extend several microns away throughout the cell monolayer-tethering bacteria. DNA in bacteria and eukaryotic cells was stained red with propidium iodine. (F) Demonstration that the fibers produced by EDL933 $h$ cpA(pJX22) adhering to HT-29 cells are HCP as determined by immunogold labeling SEM using anti-HCP antibody. Original magnification, $\times 15,000$. (G and $\mathbf{H}$ ) Production of HCP demonstrated by flow cytometry. (I) Western blotting of whole bacterial cell extracts showing lack of HcpA in the hcpA mutant.

vation fields (Figure 4, C and D). These data indicated that overexpression of $h c p A$ alone or together with $h c p B$ and $h c p C$ was sufficient for assembly of HCP but also that the addition of $\mathrm{HcpB}$ and $\mathrm{HcpC}$ assembly factors in the $h c p A$ mutant was sufficient to increase the amount of HCP produced. The long bundles of pili produced by EDL933 $\Delta h c p A$ complemented with pJX12 or pJX22 were decorated with anti-HCP antibodies and secondary antibodies conjugated to $30-\mathrm{nm}$ gold particles, as determined by immuno-SEM (Figure 4F). No gold particles were observed in the control with preimmune serum (data not shown). The specificity of the anti-HCP antiserum was further demonstrated with whole-cell extracts of EDL933 (Figure 4I), in which only the reactive HcpA protein was detected.

To judge the significance of the loss of HCP, EDL933 $\Delta b c p A$ was used to measure adherence to human colonic cells (T84, HT-29, and Caco2), nonintestinal (HEp-2 and HeLa) cell lines, and bovine (MDBK) cultured epithelial cells. The 85-170 $\Delta h c p A$ strain was tested only for adherence to MDBK and HT-29 cells. For these infection experiments, we propagated all the strains overnight in Minca medium at $37^{\circ} \mathrm{C}$ in order to activate them for the production of HCP. The light microscopy images of infected, Giemsa-stained cells show obvious impairment of adherence of the $h c p A$ mutant as compared with the wild-type and the complemented strains (Figure 5).

The level of impairment in adherence of EDL933 $\Delta h c p A$ was determined by counting bacteria adhering to several human colonic cell lines after extensive washing and cell lysis. Depending on the cell line employed, mutation of the $h c p A$ gene resulted in a 3 - to 5 -fold decrease in adherence relative to EDL933 $(P<0.0001)$ (Figure 6). Complementation of the $h c p A$ mutant with pJX22 increased adherence $(P<0.0001)$ to a level slightly higher than that seen in the parental strain. The increase in adherence might correlate with the abundant HCP produced by this strain (Figure 4D). The $h c p A$ mutant grew normally in LB broth, ruling out a growth defect as the cause of the reduced adherence. Adherence of EHEC was greatly, although not completely, reduced by the $h c p A$ deletion, indicating that other colonization factors (e.g., intimin-Tir 

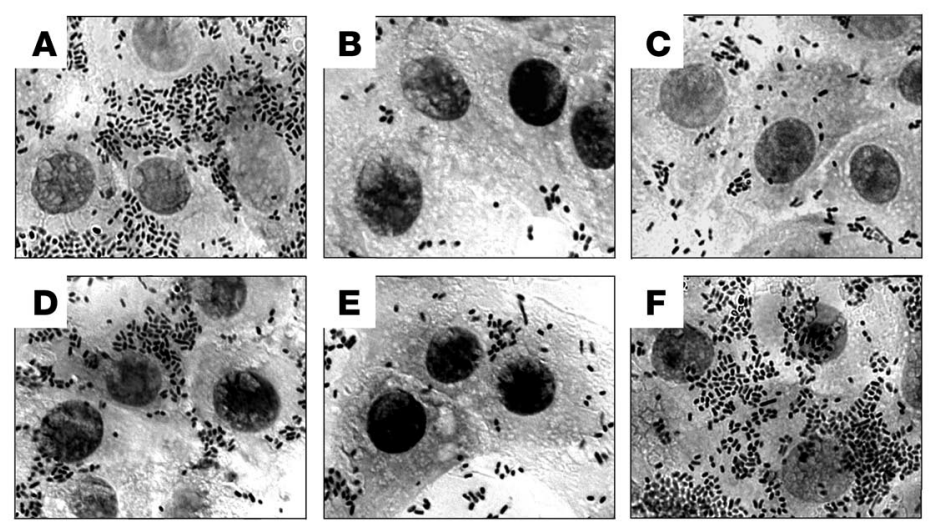

Figure 5

Qualitative comparison of adherence of wild-type EDL933 and derivative mutants to HT-29 cells. (A) EDL933; (B) EDL933 $\operatorname{escN}$ (T3SS-ATPase

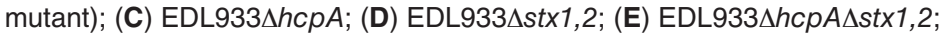
and (F) EDL933 $\Delta h c p A(p J X 22)$. HT-29 cell monolayers were incubated with these strains for 6 hours as described in Methods.

and ECP) contribute to EHEC adherence to different cell lines. We also observed reduction of adherence by EDL933 $\Delta h c p A$ to other human nonintestinal (HeLa and HEp-2) and bovine (MBDK) cell lines tested (data not shown). Taken together, the data strongly indicate that HCP mediates adherence to various epithelial cell lines, perhaps by recognition of a common surface receptor.

Adherence to pig and cow intestinal explants. Intestinal explants obtained from a 3-week-old healthy pig (ileum and colon) and from cow colon were used in quantitative experiments to compare the ability of HCP-producing strains and the $h c p A$ mutant to adhere. In agreement with the results obtained with the tissue culture adherence assays, the $h c p A$ mutant was also impaired in adherence to the animal intestinal tissue in comparison with the HCP-producing strains (Figure 7). Taken together, the adherence data strongly suggest that HCP are intestinal colonization factors with affinity for human, bovine, and porcine epithelial cells. We sought to determine whether EHEC would produce HCP while adhering to animal intestinal explants. Thin sections of infected pig tissues were reacted with anti-HCP antibodies by IFM, and we found that HCP are produced by EDL933 during interaction with pig intestinal tissue and not by the $h c p A$ mutant (Figure 8). We found that wild-type EDL933, the complemented $\Delta h c p A$ (pJX22), and the Stx mutant adhered abundantly to mucus and cellular debris present on the luminal surface of the intestinal mucosa. Fewer bacteria were multifocally adhered to the serosa; observed within the tunica muscularis, submucosa, and denuded villi; and occasionally adhered to sloughed villous epithelium (Figure 9, $\mathrm{A}, \mathrm{C}$, and E). In contrast, the $h c p A, b c p A s t x 1,2$, and $e s c N$ mutants adhered in small numbers to the intestinal mucosa (Figure 9, B, $\mathrm{D}$, and F). Another interesting observation was that pig explants infected with EDL933, EDL933 $\Delta h c p A(\mathrm{pJX} 22)$, and EDL933 $\Delta t x 1,2$ lost their normal architecture, as the intestinal lining epithelium was basically destroyed, as compared with mock-infected tissue (Figure 9, A, C, E, and G). In contrast, the tissues infected with the $h c p A, h c p A, s t x 1,2$, and $e s c N$ mutants showed less damage (Figure 9, $B, D$, and F). These data would suggest that the presence of and adherence mediated by HCP is important for colonization of the intestinal mucosa and for subsequent tissue damage.
Relationship between the intimin-Tir interaction, HCP-mediated adherence, and cytotoxicity. EHEC causes AE lesions via the intimin-Tir interaction, which is strictly dependent on the function of the T3SS. In some pathogenic bacteria such as $P$. aeruginosa, TFP are not specifically required for contact-dependent T3SS-translocation of exoenzymes (50). In enteropathogenic E. coli (EPEC), initial attachment to host cells is thought to be mediated by TFP, and T3SS is required in the formation of AE lesions $(39,51,52)$. Here, we explored the contribution of T3SS (intimin-Tir interaction), HCP, and cytotoxicity on adherence to host cells. We set out to investigate whether HCP-mediated adherence was a prerequisite for intimate attachment to host cells or whether T3SS-dependent adherence led to activation of HCP production. To test this hypothesis, we employed HCP and T3SS mutants in comparative and quantitative adherence assays. In addition, we included double stx 1,2 and triple $h c p A s t \times 1,2$ mutants to determine how Stx might influence the outcome of the interaction of EHEC with host cells. First, we tested the EDL933 hсpA mutant for production of T3-secreted proteins EspA, B, and $\mathrm{D}$ and found that this strain was able to produce Esps at the same level as the wild-type strain (Supplemental Figure 3 ), suggesting that the $h c p A$ mutant remains capable of recruiting actin and inducing the formation of AE lesions. This notion was confirmed by the fluorescent actin-staining assay, which allowed detection of actin condensation in host cells beneath adhering bacteria (data not shown). Second, we found that EDL933 mutated in $\operatorname{esc} N$ (a T3SS-associated ATPase gene) was significantly reduced in adherence to colonic cell lines $(P<0.0001)$, even more than the $h c p A$ mutant (Figure 5, B and C, and Figure 6). Last, the mutation in $s t \times 1,2$ genes in EDL933 had a negative effect in adherence but not as significant as the mutation in escN, $h c p A$, or $h c p A s t x 1,2$ (Figures 5 and 6). EHEC strain 85-170, which lacks Stx production, remains capable of adhering to host cells, further indicating that cytotoxicity is not required for HCP-mediated adherence (Supple-

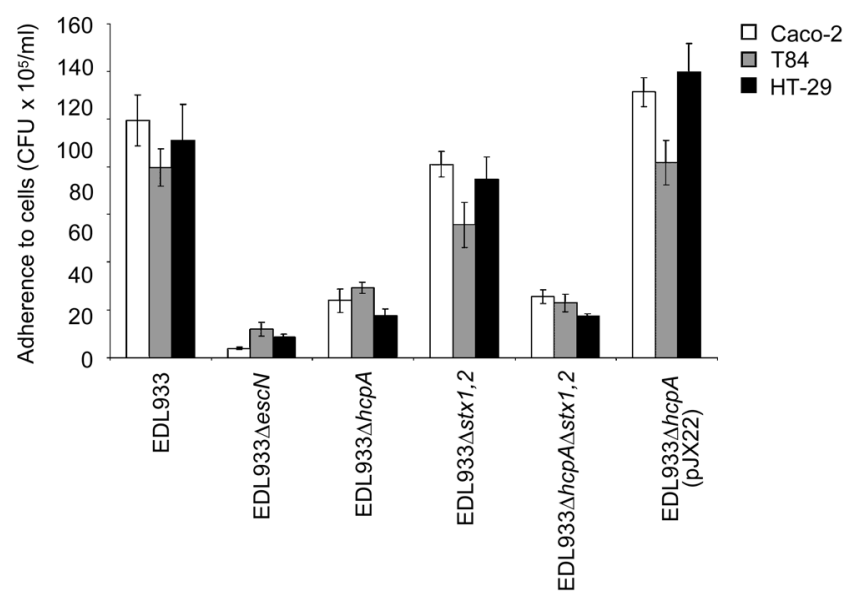

\section{Figure 6}

Quantification of bacterial adherence to human intestinal cells. The indicated strains were incubated with human colonic Caco-2, T84, and HT-29 cells for 6 hours and the adherent bacteria expressed as CFUs after plating serial dilutions. The data are representative of at least 3 experiments performed in triplicate. Note the significant reduction in adherence in the EDL933 $4 h c p A$ and EDL933 $\Delta$ esc $N$ strains compared with the wild type to all the cell lines tested. 


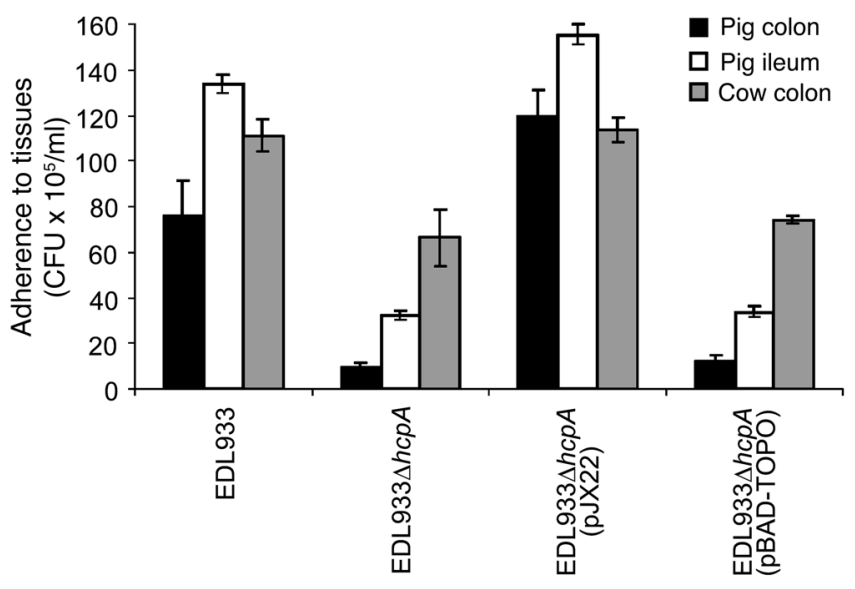

Figure 7

Adherence of EHEC strains to pig and cow intestinal explants. Pig (ileum and colon) and cow (colon) gut tissues were cut into squares of $8 \times 8 \mathrm{~mm}$ and $0.8 \mathrm{~g}$ of weight, washed, and incubated for 6 hours in DMEM with cultures of EDL933, EDL933 $\Delta h c p A$, EDL933 $\Delta h c p A(p J X 22)$, and EDL933 $\Delta h c p A$ (pBAD-TOPO) obtained in Minca broth. Shown is the average of 3 experiments performed in triplicate. Note the reduction in adherence to animal intestinal sections of the hcpA mutant.

mental Figure 2). Thus, these results provokingly suggest that T3SS-associated functions and HCP act synergistically to mediate EHEC attachment and colonization. Taken together, these experiments have shed light into the sequence and relevance of adherence events and mechanisms employed by EHEC O157:H7.

Inbibition of adherence with HCP antibodies. Rabbit antibodies directed against purified HCP were used to test their ability to block adherence of 3 EHEC O157:H7 strains (EDL933, 86-24, and 85-170). A striking dose-dependent inhibition was observed with the 3 strains used but in particular with strains 86-24 and 85-170 (>90\% inhibition) (Figure 10). The difference observed between the strains is an indication that the inhibition is not due to the presence of anti-O157 antibodies in the serum employed. These observations further support a role for HCP in adherence to host cells.

\section{Discussion}

The epidemiological renaissance and clinical significance of EHEC food-borne infections have stimulated increased interest in the understanding of the pathogenic mechanisms of this deadly organism (7). While it is well established that EHEC colonizes the human colonic mucosa and the terminal rectum of bovines (20), it is not clear what role pili play in host colonization. TFP have not been previously observed in EHEC O157:H7. Many functions associated with pathogenicity in Gram-negative bacteria are attributed to TFP, including twitching motility, adherence to host cells, biofilm formation, DNA uptake, phage attachment, cell signaling, and evasion of immune system (37). In this study, we provide compelling evidence that clearly show that EHEC O157: $\mathrm{H} 7$ is able to assemble type IV pilin HcpA into long bundles of pili, which we designate HCP. Analogous to the role that TFP play as colonization factors in other pathogenic bacteria, we hypothesized that HCP are colonization factors of EHEC. We found that HCP are involved in adherence of EHEC O157:H7 to human intestinal (colonic) and nonintestinal cell lines, bovine (kidney) epithelial cells, and to pig and cow gut explants. Our observa- tion that $h c p A$ mutants exhibited a significant decreased attachment to cultured epithelial cells (HT-29, T84, Caco2, HEp-2, HeLa, and MDBK) that could be restored to full adherence by complementation with $h c p A$ alone or in association with $h c p B C$ is a strong indication that HCP promote bacterial adherence to host intestinal and nonintestinal epithelial cells. The comparative adherence studies also revealed that additional adherence factors are still present in EHEC, as the $h c p A$ mutants showed some residual adherence to cultured human and bovine epithelial cells. The residual adherence could be attributed to the presence of intimin-Tir and the production of ECP.

It has been suggested that the terminal rectum, rather than the intestine, is the primary colonization site of EHEC O157:H7 in bovines and that components encoded by the LEE4 operon are required for rectal colonization (20). In this context, HCP might play an accessory role in the colonization of the bovine host in association with other LEE- or non-LEE-encoded adhesins. Gnotobiotic pigs have been used as a model to study events of EHEC pathogenesis. In fact, the role of intimin as an adhesin in vivo was demonstrated in a porcine model (21). We employed porcine and bovine intestinal explants to study the role of HCP as a colonization factor in vitro. As predicted, the $h c p A$ mutant was impaired in adherence to animal tissue as compared with HCP-producing strains. Interestingly, we showed that HCP are produced by EDL933 infecting pig intestinal tissue, as thin sections of infected pig explants reacted with anti-HCP antibody by IFM. Considerable tissue damage was observed by the wild type, the Stx mutant, and the EDL933 $\Delta h c p A(\mathrm{pJX} 22)$ while the explants incubated with
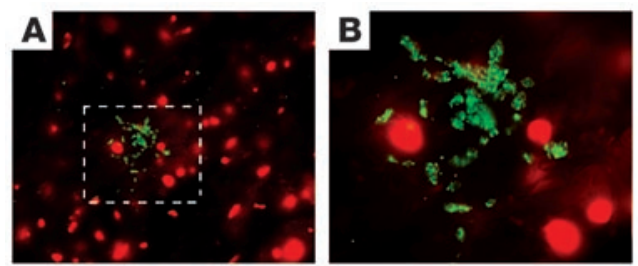

EDL933
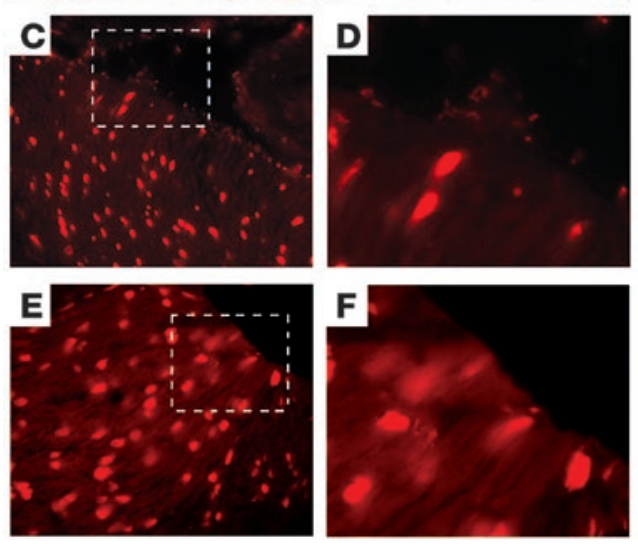

EDL933 $\triangle h c p A$

Figure 8

Detection of HCP on thin sections of infected pig intestinal explants. After infection with the wild-type EDL933 (A) or the EDL933 $4 h c p A$ (C), the tissues were sliced and immunostained with anti-HCP antibody. The DNA of pig intestinal cells and the bacteria are stained in red (with propidium iodide) while HCP are stained in green. Note the absence of HCP in the hcpA mutant. Mock-infected tissues (E) were used as negative controls. B, D, and $\mathbf{F}$ are enlarged images of $\mathbf{A}, \mathbf{C}$, and $\mathbf{E}$, respectively. 

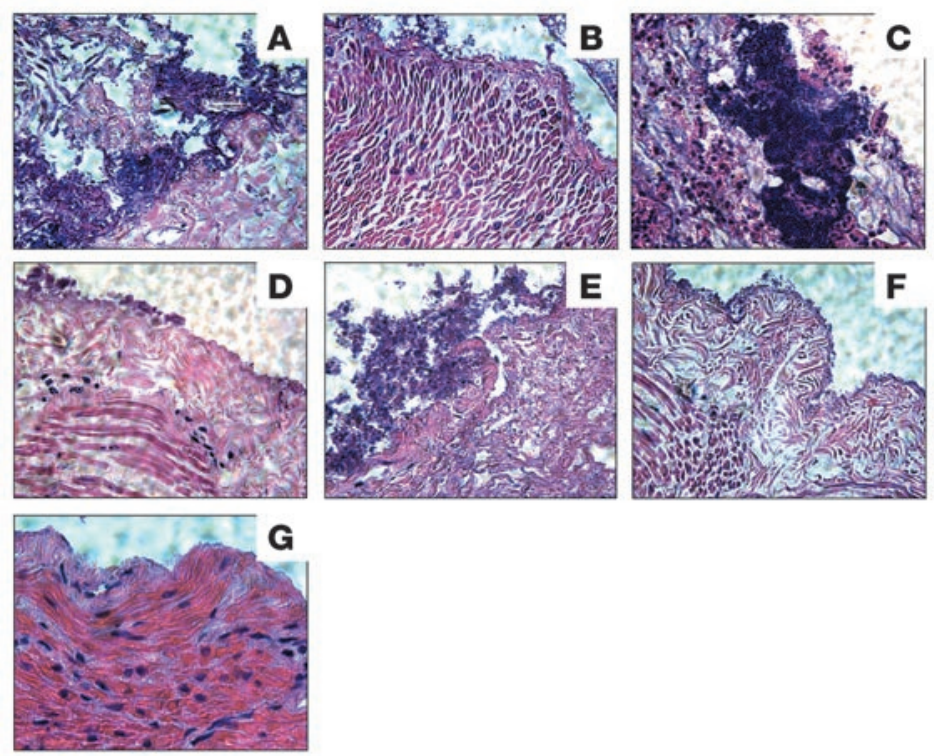

Figure 9

Pig ileum infected with EHEC strains, sliced, and stained with H\&E. (A) EDL933; (B) EDL933 $h$ cpA; (C) EDL933 $\Delta h c p A$ (pJX22); (D) EDL933 $\Delta e s c N$; (E) EDL933 $\Delta s t x 1,2$; (F) EDL933 $\Delta h c p A \Delta s t x 1,2$; and (G) mock infected. See text for description.

$b c p A$ mutant retained their apparent normal architecture. In all, these data are compelling evidence that support our hypothesis that HCP are intestinal colonization factors.

The intimin-Tir interaction, which is dependent on the presence and function of the T3SS, is crucial for the development of intimate attachment and effacing of the enterocyte membrane, although not enough to mediate attachment in the absence of HCP. In addition to their central role in cytotoxicity and the development of HUS, Stx have been reported to induce the expression of surface-exposed nucleolin on mammalian cells (24), which acts as an alternative receptor for intimin. We explored whether T3SSdependent or Stx-induced adherence was a requirement or a consequence of the adherence mediated by HCP to cultured epithelial cells. To this aim, we analyzed in comparative and quantitative assays the ability of $\operatorname{esc} N, \operatorname{stx} 1,2, h c p A$, and $h c p A s t x 1,2$ mutants to adhere to various human intestinal colonic cell lines. Under our experimental conditions, EHEC strain 85-170, which does not produce Stx, adhered to colonic cells as efficiently as Shiga-toxigenic EDL933. When the stx1,2, and $h c p A$ genes were interrupted in EDL933 and 85-170 was mutated in $h c p A$, we found that both mutants showed levels of adherence similar to those of the single EDL933 hcpA mutant. These results suggest that HCP-mediated adherence is independent of cytotoxicity and that Stx-mediated adherence does not contribute to the function of HCP. When the intimin-Tir interaction and HCP-mediated adherence were compared, we observed that the level of adherence of the esc $N$ mutant (unable to translocate Tir) and the $h c p A$ mutant were 6- to 27-fold and 3 - to 5-fold (depending on the cell line employed), respectively, in comparison with the wild-type strain. These results further support that the functional T3SS and the intimin-Tir-mediated adherence are central to EHEC interaction with host cells and strongly suggest that HCP functions as an important accessory colonization factor. The results of the ultrastructural and IFM studies obtained here strongly suggest that HCP contribute to consolidate the formation of infectious units by bridging bacteria. However, we cannot exclude the possibility that HCP also mediate direct contact of the bacteria to a particular receptor, which is apparently widely distributed among intestinal and nonintestinal cells. For P. aeruginosa, the contact-dependent translocation of exoenzymes and cytotoxins via T3SS occurs independently of TFP (50). Whether HCP acts at early or late stages of the colonization process requires further investigation.

Our investigation of the in vitro conditions for pilus production in wild-type EHEC O157:H7 strains, using different growth environments and culture media, revealed that EHEC produces HCP after growth in Minca medium (42) and in contact with host cells. The data would suggest that, like TFP production in other pathogens $(53,54)$, the production of HCP in EHEC O157:H7 is probably tightly regulated. It is possible that growth of the bacteria in Minca relieves the negative regulation exerted in other growth conditions by an unknown repressor or that signals present in Minca induce the expression of a specific activator. We speculate that the environmental and nutritional signals that trigger HCP production must resemble those found in vivo, perhaps during colonization of the large intestine of animals and humans, and efforts are underway to identify these precise signals.

Earlier studies showed that laboratory or pathogenic

E. coli strains were unable to produce HcpA-containing (PpdD-containing) pili, even when expression levels of both $h c p A$ / $p p d D$ and assembly genes ( $h c p B / h \circ f B$ and $h c p C / h o f C$ ) were increased. Production of PpdD pili was only observed in a heterologous host such as $P$. aeruginosa lacking endogenous TFP (49) or in E. coli producing the pullulanase type II secreton of Klebsiella oxytoca (55). The fact that HCP are produced in EHEC O157:H7 strains suggests the presence of a TFP biogenesis machinery and regulatory genes that are absent or are defective in E. coli K-12 $(45,49)$. Assembly of TFP requires, depending on the organism, from 16 to 40 biogenesis genes (37). Genetic complementation studies involving the transfer of $h c p A B C$ genes on a plasmid expressed from an inducible promoter to the EHEC HCP mutant yielded a strain that was able to hyperproduce HCP. This would suggest that the induction of

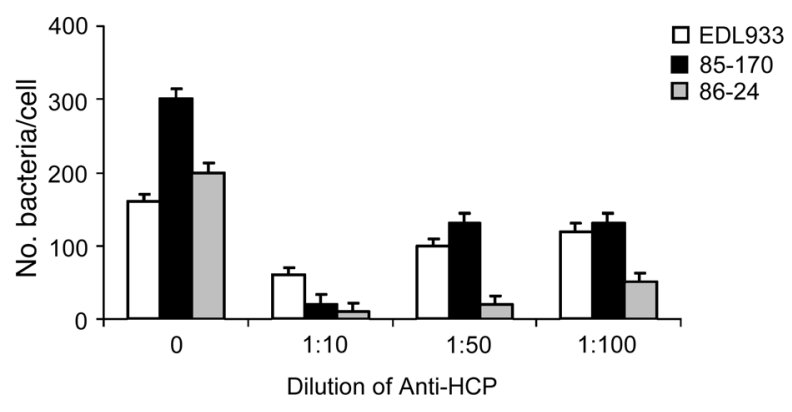

Figure 10

Inhibition of EHEC adherence by anti-HCP antibodies. EDL933 was preincubated with 1:10,1:50, and 1:100 dilutions of anti-HCP antibody for 30 minutes before our standard 6-hour adherence assay. Adherence (number of bacteria per cell) was recorded visually under a light microscope. The experiments were repeated at least 3 times in triplicate. Note the dose-response inhibition seen with high concentration of antibodies. 
Table 1

E. colistrains and plasmids used

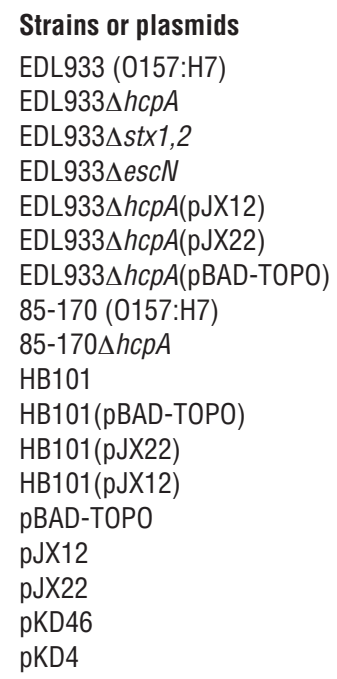

\begin{tabular}{|c|c|}
\hline Notes & Source \\
\hline Wild type & (1) \\
\hline $\mathrm{EDL} 933 \Delta h c p A: \mathrm{km}$ & This study \\
\hline EDL933 $\Delta s t x 1,2: \mathrm{cm}$ & This study \\
\hline EDL933 $\Delta e s c N: k m$ & $(62)$ \\
\hline hcpA mutant complemented with pJX12 & This study \\
\hline hcpA mutant complemented with pJX22 & This study \\
\hline hcpA mutant transformed with $\mathrm{pBAD}-\mathrm{TOPO}$ & This study \\
\hline Wild type, Stx- & (63) \\
\hline 85-170 & This study \\
\hline E. coli $\mathrm{B} / \mathrm{K}-12$ hybrid & (64) \\
\hline HB101 transformed with pBAD-TOPO & This study \\
\hline HB101 complemented with pJX22 & This study \\
\hline HB101 complemented with pJX12 & This study \\
\hline Cloning expression vector, $\mathrm{Ap}^{r}$ & Invitrogen \\
\hline EHEC hcpA cloned in pBAD-TOPO & This study \\
\hline EHEC hcpABC cloned in pBAD-TOPO & This study \\
\hline Plasmid containing the red recombinase & $(56)$ \\
\hline Km cassette & (56) \\
\hline
\end{tabular}

Source

his study

is study

his study

This study

(64)

his study

This study

nvitrogen

is study

$(56)$

pKD4 (Table 1) (56). Primers G336 and G337 were used for mutagenesis of stx1,2. Primers flanking the $h c p A$ (G98 and G99) or stx1,2 (G338 y G339) genes as well as primers inside the kanamycin resistance gene (K1 and $\mathrm{K} 2$ ) were used to confirm the required gene replacement by PCR. The resulting $h c p A$ mutants in EDL933 and 85-170 were named EDL933 $\Delta b c p A$ and $85-170 \Delta h c p A$, respectively. To complement $h c p A$ mutants, $h c p A$ alone or together with the $h c p B C$ genes was amplified from EDL933 using the primers listed in Table 2 and cloned into the NcoI site and thymidine overhang of PBAD-TOPO. The resulting plasmids (pJX12 and pJX22) were obtained in HB101 and then electroporated into the $h c p A$ mutants to yield EDL933 $h c p A(\mathrm{pJX} 12)$ and EDL933 $h c p A(\mathrm{pJX} 22)$. Expression of genes under araBAD promoter control was induced with $0.8 \%$ arabinose.

Antisera. Rabbit antibody against an E. coli $\mathrm{K}-12$ PpdD-GST fusion was used after $4 \times$ adsorption with the EDL933 hcpA mutant to remove nonspecific antibodies. This antibody is referred to as anti-HCP in the text. Antisera against EspA, EspB, and $\mathrm{EspD}$ were available from previous studies

only these 3 genes is sufficient for HCP production. We cannot rule out that other genes present in the chromosome of EHEC are important for HCP biogenesis. The $h c p A B C$ genes are remarkably well conserved in E. coli, Shigella, and several other enterobacterial species, suggesting that under certain environmental conditions, HCP might be produced by these organisms and play an important role in adaptation and survival.

The elucidation of the detailed mechanisms of colonization of human and bovine hosts will be important to further our understanding of EHEC pathogenesis and in the development of strategies to prevent EHEC infections. In this context, HCP should be considered an accessory colonization factor that together with intimin-Tir and ECP contributes to the colonization of the gastrointestinal tract of humans and bovines.

\section{Methods}

Bacterial strains and culture conditions. Bacterial strains and plasmids used in this study are listed in Table 1. Bacteria were routinely cultured in LB broth at $37^{\circ} \mathrm{C}$ with shaking, unless otherwise stated. When required, antibiotics kanamycin $(100 \mu \mathrm{g} / \mathrm{ml})$ and ampicillin $(100 \mu \mathrm{g} / \mathrm{ml})$ were added to the media. Minca minimal medium (1.36 g K ${ }_{2} \mathrm{PO}_{4}, 10.1 \mathrm{~g} \mathrm{Na}_{2} \mathrm{HPO}_{4} .2 \mathrm{H}_{2} \mathrm{O}$, $1 \mathrm{~g}$ glucose, $1 \mathrm{~g}$ casaminoacids, $10 \mathrm{~g} \mathrm{MgSO}_{4} .7 \mathrm{H}_{2} \mathrm{O}, 1 \mathrm{~g} \mathrm{MnCl} 2.4 \mathrm{H}_{2} \mathrm{O}$, $0.135 \mathrm{~g} \mathrm{FeCl}_{3} .6 \mathrm{H}_{2} \mathrm{O}$, and $0.4 \mathrm{~g} \mathrm{CaCl}_{2} .2 \mathrm{H}_{2} \mathrm{O}$ per liter adjusted to $\mathrm{pH} 7.5$ ) (42) was used for production of HCP and for preparing bacterial cultures for comparative adherence assays. Arabinose was used at $100 \mathrm{mM}$ in LB broth to induce $\lambda$ red recombinase production from plasmid pKD46 (56). For induction of the pBAD-TOPO inducible promoter, $0.8 \%$ arabinose was added to the medium.

DNA manipulations. Agarose gel electrophoresis, transformation, PCR, restriction enzyme digestions, ligation, and other routine DNA procedures were carried out as previously described (57).

Construction of EHEC pili mutants. The $\lambda$ red recombinase system was used to construct $h c p A$ nonpolar deletion mutants of EHEC O157:H7 strains EDL933 and 85-170 (56). G68 and G69 primers, homologous to sequences within the $5^{\prime}$ and $3^{\prime}$ ends of the $h c p A$ gene, were used to replace this gene with a kanamycin-resistance cassette derived from the template plasmid
$(58,59)$. Human sera obtained from HUS patients that gave informed consent and were a kind gift of Phillip Tarr (Washington University, St. Louis, Missouri, USA) to James B. Kaper, and normal human sera were obtained from the collection of the Center for Vaccine Development, University of Maryland.

Electron microscopy and immunogold labeling. For TEM, a drop $(10 \mu \mathrm{l})$ of bacterial culture or pili sample was placed on a Formvar carbon-coated grid for 3 minutes, negatively stained with $1 \%$ sodium phosphotungstic acid ( $\mathrm{pH}$ 7.2) for 1 minute, and examined under a Philips transmission electron microscope. For immunogold EM, bacteria were mixed with anti-HCP sera diluted 1:10 in PBS containing 1\% (wt/vol) BSA for 1 hour and washed with PBS-BSA. Goat anti-rabbit immunoglobulin labeled with 10-nm gold particles (BB International) diluted 1:10 in PBS-BSA was used to detect antibodies bound to pili and then negatively stained as above (58). For SEM, infected cells were fixed with $2 \%$ formalin in PBS, postfixed with $1 \%$ osmium tetraoxide, dehydrated by sequential ethanol concentrations, dried to critical point, and coated with a mixture of gold and palladium. Specimens were examined in a high-resolution Leo scanning electron microscope.

Pilus purification. HCP produced by EDL933 were detached from the bacteria cultivated in 40 plates $(150 \times 15 \mathrm{~mm})$ of Minca agar supplemented with $0.8 \%$ arabinose by vigorous shaking. Pilus purification was monitored by TEM and SDS-PAGE, as previously described (39). In brief, bacteria were separated by centrifugation at $10,000 \mathrm{~g}$ for 30 minutes, and the supernatant was centrifuged at $18,000 \mathrm{~g}$ for 30 minutes to remove flagella, outer membranes, and bacterial debris. The pili-containing supernatant was centrifuged at 78,000 $\mathrm{g}$ for 2 hours and the pellet dissolved in distilled water and then loaded onto a cesium chloride/ $1 \%$ Sarkosyl gradient (density $1.2 \mathrm{~g} / \mathrm{ml}$ ) to obtain relatively pure pili (58). The gradient was centrifuged at $50,000 \mathrm{~g}$ for 24 hours at $18^{\circ} \mathrm{C}$, after which an opaque thick band was seen in the middle of the gradient. The material in this band was recovered by lateral puncture, dialyzed against distilled water, and observed by TEM.

SDS-PAGE and Western blotting analyses. Pili preparations from the purification steps and normalized whole-cell lysates were separated by SDSPAGE on $16 \%$ acrylamide gels (60). Western blotting was carried out using 


\section{Table 2}

List of primers used

\begin{tabular}{|c|c|c|}
\hline Name & Gene & Sequence $\left(5^{\prime}\right.$ to $\left.3^{\prime}\right)$ \\
\hline G68 & hсрA/P1 & AATCAAGGAGCGAAACAGATGGACAAGCAACGCGGTTTTACATGTAGGCTGGAGCTGCTTCG \\
\hline G69 & hсрА/P2 & AATATTCATTGCCGCTCCTTAGTTGGCGTCATCAAAGCGGAACATATGAATATCCTCCTTAG \\
\hline G80 & hсpAFNcol & ACCATGGACAAGCAACGCGGT \\
\hline G82 & hсpARstop & TTAGTTGGCGTCATCAAAGC \\
\hline G83 & hcpAstop & TTATCCСАТСССАСТCATCG \\
\hline G98 & hсpA-F & TCGCTAGTTGCTGACAGATTT \\
\hline G99 & hсрA-R & AATGTCTGTTGTGTGCGACTG \\
\hline G336 & stx1,2/P2 & TTTCACTGAGCTATTCTAAGTCAACGAAAAATAACTTCGGTGTAGGCTGGAGC \\
\hline G337 & stx1,2/P1 & CAAGGAGTATTGTGTAATATGAAAATAATTATTTTTAGACATATGAATATCCT \\
\hline G338 & stx1,2-F & TGCGTAACAGCATTTTGCTC \\
\hline G339 & stx1,2-R & CTATGTGCCATTGCATGGTG \\
\hline K1 & $\mathrm{Km}^{\mathrm{r}}$ cassette & GCCCAGTCATAGCCGAATAGCCT \\
\hline K2 & $\mathrm{Km}^{\mathrm{r}}$ cassette & CGGTGCCCTGAATGAACTGCAGG \\
\hline PpdDE & $p p d D F$ & CTATTCGAATTCAAAGTAGCGCCAACCAAATC \\
\hline PpdD4 & $p p d D \mathrm{R}$ & CTATAGGGATCCGCAGACACATTTCAGTGAGC \\
\hline
\end{tabular}

anti-HCP antibody at a dilution of 1:2,000 and a horseradish peroxidase conjugate $(1: 20,000)$. Blots were developed with HyGLO chemiluminescent HRP antibody detection reagent (Denville Scientific Inc.).

Mass spectrometry. A protein band of $19 \mathrm{kDa}$ was excised from polyacrylamide gels and subjected to mass spectrometry analysis after digestion with trypsin at the Proteomics Core Facility at the College of Pharmacy, University of Arizona.

Flow cytometry. Flow cytometry was used to detect the expression of HCP produced by EHEC O157:H7 strains grown overnight at $37^{\circ} \mathrm{C}$ in Minca media. The cultures were adjusted to an optical density $\left(\mathrm{OD}_{600}\right)$ of 1.1 , and $45-\mu \mathrm{l}$ aliquots were incubated for 1 hour on ice with $25 \mu \mathrm{l}$ of anti-HCP using a dilution of 1:1,000. After 3 gentle washes with PBS, the bacteria were suspended in $25 \mu$ l of a dilution of goat anti-rabbit IgG $(\mathrm{H}+\mathrm{L})$ Alexa Fluor conjugate (Invitrogen). After 1-hour incubation at $4{ }^{\circ} \mathrm{C}$, the bacteria were gently washed 3 times with PBS and resuspended in 800- $\mu$ l final volume of PBS. For the analysis, the bacteria were labeled with $5 \mu \mathrm{l}$ of a propidium iodide solution (Sigma-Aldrich). Propidium iodide was visualized through a 42-nm band pass centered at $585 \mathrm{~nm}$. These experiments were repeated 3 times in triplicate. The FITC fluorescence emission was collected through a $30-\mathrm{nm}$ band-pass filter centered at $530 \mathrm{~nm}$ in which 50,000 events were measured. The samples were analyzed at the ARL Biotechnology/ACCC Cytometry Core Facility at the University of Arizona, by using a FACScan (BD).

Bacterial adherence to epithelial cells. We employed human polarized intestinal colonic epithelial cells (HT-29, T84, and Caco2) and nonintestinal cells (HeLa and HEp-2) as well as bovine kidney (MDBK) cell lines. These cells were cultivated at $37^{\circ} \mathrm{C}$ under $5 \% \mathrm{CO}_{2}$ atmosphere in polystyrene 24well plates (CellStar) containing glass coverslips, as previously described (58). For the adherence assay, cell monolayers at $60 \%-80 \%$ confluency were washed and reconstituted with DMEM (Invitrogen). As inoculum, we used $10^{7}$ bacteria grown overnight in Minca broth at $37^{\circ} \mathrm{C}$. The cells were infected from 3 to 6 hours, washed with PBS to remove unbound bacteria, fixed with $2 \%$ formalin/PBS for 20 minutes, and stained with Giemsa for 20 minutes. The coverslips were mounted on glass slides to be observed by light microscopy. For quantitative assessment of bacterial adherence (wild type versus mutants) to epithelial cells, cell monolayers were treated with $1 \mathrm{ml}$ of $0.1 \%$ Triton X-100 for 5 minutes. Following lysis, bacteria were quantified by plating out 10 -fold dilutions of the bacterial suspensions. Quantifications were performed in triplicate on 3 different days, and the results were expressed as adhering CFUs. To evaluate growth fit- ness of $h c p A$ mutants compared with wild-type strain, overnight cultures were standardized to an $\mathrm{OD}_{600}$ of 1.0 and diluted $1: 100$ in $100 \mathrm{ml} \mathrm{LB}$ in a $250 \mathrm{ml}$ flask. All cultures were incubated at $37^{\circ} \mathrm{C}$ with shaking $(200 \mathrm{rpm})$. Growth of each bacterial strain was assessed by measuring $\mathrm{OD}_{600}$ every 30 minutes for a total of 8 hours.

Immunofluorescence. Primary anti-HCP antibodies were added to formalin-fixed cells for 1 hour in $10 \%$ horse serum followed by the appropriate secondary Alexa Fluor conjugate and then visualized using an Axio Imager 1.0 Zeiss microscope as previously described (58).

Inhibition of adherence with antibodies. Antibodies against HCP were used to test their ability to block adherence by 3 EHEC O157:H7 strains, namely EDL933, 86-24, and 85-170. Before the 6-hour HT-29 cell adherence assay described above, $10 \mu \mathrm{l}$ of the bacterial inoculum were incubated for $30 \mathrm{~min}$ utes with 1:10, 1:50, and 1:100 dilutions of the anti-HCP and preimmune sera in triplicate. The number of adhering bacteria per cell in each sample was determined by direct observation of Giemsa-stained infected MDBK cells under a light microscope. At least 10 fields per sample were observed, and the average obtained was plotted.

Adherence to pig and cow intestinal explants. Animal tissues for this work were obtained after approval of animal protocol ID 07-D/I-009-A/H approved by the Institutional Animal Care and Use Committee (IACUC) and the Institutional Biosafety Committee, Iowa State University. Intestinal tissue (ileum and colon) from 3-week-old pigs and bovine colon (a gift from the Meat Science Laboratory, University of Arizona) was obtained as previously described (61). The tissues were rinsed thoroughly with HEPES-Hanks buffer ( $\mathrm{pH} 7.4$ ), cut into $8 \times 8 \mathrm{~mm}$ squares (0.8 g of weight), and split open with a scalpel, then flushed with HEPES-Hanks buffer ( $\mathrm{pH} 7.4$ ) to remove debris. The tissues were incubated for 6 hours with $10 \mu \mathrm{l}$ of bacteria grown overnight in Minca broth to induce activation of HCP. We employed EDL933, EDL933 $\Delta h c p A$, EDL933 $\Delta h c p A(\mathrm{pJX} 22)$, and EDL933 $\Delta h c p A(\mathrm{pBAD}-\mathrm{TOPO})$ strains. After infection, unbound bacteria were removed by washing with HEPESHanks buffer, and the attached bacteria were detached by vortexing for 10 minutes with glass beads and then serially diluted and plated on MacConkey sorbitol agar to obtain CFUs. The results shown are the mean of 3 experiments performed in triplicate.

Statistics. Data corresponding to adherence assays were compared using ANOVA and then the Tukey test. The significance level was $5 \%$ in all tests. The SPSS statistical package was used. 


\section{Acknowledgments}

We thank Anthony Pugsley for critical discussion and reading of the manuscript; Phillip Tarr for providing human HUS sera to J.B. Kaper; María Rendón and Alejandra Vázquez for technical assistance; and Partha Samadder for helpful discussions. This work was supported by grant 7015 from the Arizona Biomedical Research Commission (to J.A. Girón); NIH grants AI60211 and AI06102001 (to J.A. Girón) and DK58957 and AI21657 (to J.B. Kaper); and grants from DGAPA (IN201703-3), CONACyT (42918Q), and
HHMI (75301-565101) (to J.L. Puente). J.A. Girón thanks the Arizona Hispanic Center of Excellence for support.

Received for publication October 23, 2006, and accepted in revised form August 13, 2007.

Address correspondence to: Jorge A. Girón, Department of Immunobiology, University of Arizona, $1501 \mathrm{~N}$. Campbell Ave., Tucson, Arizona 85724, USA. Phone: (520) 626-0104; Fax: (520) 626-2100; E-mail: jagiron@email.arizona.edu.
1. Riley, L.W., et al. 1983. Hemorrhagic colitis associated with a rare Escherichia coli serotype. N. Engl. J. Med. 308:681-685.

2. Griffin, P.M., et al. 1988. Illnesses associated with Escherichia coli $\mathrm{O} 157: \mathrm{H} 7$ infections. A broad clinical spectrum. Ann. Intern. Med. 109:705-712.

3. Kaper, J.B., Gansheroff, L.J., Wachtel, M.R., and O’Brien, A.D. 1998. Intimin-mediated adherence of Shiga Toxin-producing Escherichia coli and attaching-and-effacing pathogens. In Escherichia coli O157:H7 and other Shiga toxin-producing E. coli strains. J.B. Kaper and A.D. O'Brien, editors. American Society for Microbiology. Washington, DC, USA. $148-156$

4. Kaper, J.B., Nataro, J.P., and Mobley, H.L. 2004 Pathogenic Escherichia coli. Nat. Rev. Microbiol. 2:123-140.

5. Nataro, J.P., and Kaper, J.B. 1998. Diarrheagenic Escherichia coli. Clin. Microbiol. Rev. 11:142-201.

6. Paton, J.C., and Paton, A.W. 1998. Pathogenesis and diagnosis of Shiga toxin-producing Escherichia coli infections. Clin. Microbiol. Rev. 11:450-479.

7. Tarr, P.I., Gordon, C.A., and Chandler, W.L. 2005. Shiga-toxin-producing Escherichia coli and haemolytic uraemic syndrome. Lancet. 365:1073-1086.

8. Caprioli, A., Morabito, S., Brugere, H., and Oswald, E. 2005. Enterohaemorrhagic Escherichia coli: emerging issues on virulence and modes of transmission. Vet. Res. 36:289-311.

9. Borczyk, A.A., Karmali, M.A., Lior, H., and Duncan, L.M. 1987. Bovine reservoir for verotoxin-producing Escherichia coli O157:H7. Lancet. 1:98.

10. Cody, S.H., et al. 1999. An outbreak of Escherichid coli $\mathrm{O} 157: \mathrm{H} 7$ infection from unpasteurized commercial apple juice. Ann. Intern. Med. 130:202-209.

11. Crump, J.A., et al. 2002. An outbreak of Escherichia coli $\mathrm{O} 157: \mathrm{H} 7$ infections among visitors to a dairy farm. N. Engl. J. Med. 347:555-560.

12. Karmali, M.A., Steele, B.T., Petric, M., and Lim, C. 1983. Sporadic cases of haemolytic-uraemic syndrome associated with faecal cytotoxin and cytotoxin-producing Escherichia coli in stools. Lancet. 1:619-620.

13. Paton, A.W., Srimanote, P., Woodrow, M.C., and Paton, J.C. 2001. Characterization of Saa, a novel autoagglutinating adhesin produced by locus of enterocyte effacement-negative Shiga-toxigenic Escherichia coli strains that are virulent for humans. Infect. Immun. 69:6999-7009.

14. McKee, M.L., Melton-Celsa, A.R., Moxley, R.A., Francis, D.H., and O'Brien, A.D. 1995. Enterohemorrhagic Escherichia coli O157:H7 requires intimin to colonize the gnotobiotic pig intestine and to adhere to HEp-2 cells. Infect. Immun. 63:3739-3744.

15. Tarr, P.I., et al. 2000. Iha: a novel Escherichia col O157:H7 adherence-conferring molecule encoded on a recently acquired chromosomal island of conserved structure. Infect. Immun. 68:1400-1407.

16. Nicholls, L., Grant, T.H.R., and Robins-Browne, R.M. 2000. Identification of a novel genetic locus that is required for in vitro adhesion of a clinical isolate of enterohaemorrhagic Escherichia coli to epithelial cells. Mol. Microbiol. 35:275-288.

17. Ashkenazi, S., May, L., LaRocco, M., Lopez, E.L. and Cleary, T.G. 1991. The effect of postnatal age on the adherence of enterohemorrhagic Escherichia coli to rabbit intestinal cells. Pediatr. Res. 29:14-19.

18. Dean-Nystrom, E.A., Bosworth, B.T., Cray, W.C., Jr., and Moon, H.W. 1997. Pathogenicity of Escherichia coli $\mathrm{O} 157: \mathrm{H} 7$ in the intestines of neonatal calves. Infect. Immun. 65:1842-1848.

19. Stavric, S., Buchanan, B., and Gleeson, T.M. 1993. Intestinal colonization of young chicks with Escherichia coli $\mathrm{O} 157: \mathrm{H} 7$ and other verotoxin-producing serotypes. J. Appl. Bacteriol. 74:557-563.

20. Naylor, S.W., et al. 2003. Lymphoid follicle-dense mucosa at the terminal rectum is the principal site of colonization of enterohemorrhagic Escherichia coli O157:H7 in the bovine host. Infect. Immun. 71:1505-1512.

21. Donnenberg, M.S., et al. 1993. The role of the eae gene of enterohemorrhagic Escherichia coli in intimate attachment in vitro and in a porcine model. J. Clin. Invest. 92:1418-1424.

22. Frankel, G., et al. 1996. The cell-binding domain of intimin from enteropathogenic Escherichia coli binds to beta1 integrins. J. Biol. Chem. 271:20359-20364.

23. Kenny, B., and Finlay, B.B. 1997. Intimin-dependent binding of enteropathogenic Escherichia coli to host cells triggers novel signaling events, including tyrosine phosphorylation of phospholipase Cgamma1. Infect. Immun. 65:2528-2536.

24. Robinson, C.M., Sinclair, J.F., Smith, M.J., and O'Brien, A.D. 2006. Shiga toxin of enterohemorrhagic Escherichia coli type O157:H7 promotes intestinal colonization. Proc. Natl. Acad. Sci. U. S. A 103:9667-9672.

25. Torres, A.G., and Kaper, J.B. 2003. Multiple elements controlling adherence of enterohemorrhagic Escherichia coli $\mathrm{O} 157: \mathrm{H} 7$ to HeLa cells. Infect. Immun. 71:4985-4995

26. Hayashi, T., et al. 2001. Complete genome sequence of enterohemorrhagic Escherichia coli O157:H7 and genomic comparison with a laboratory strain K-12. DNA Res. 8:11-22.

27. Perna, N.T., et al. 2001. Genome sequence of enterohaemorrhagic Escherichia coli O157:H7. Nature. 409:529-533.

28. Low, A.S., et al. 2006. Analysis of fimbrial gene clusters and their expression in enterohaemorrhagic Escherichia coli O157:H7. Environ. Microbiol. 8:1033-1047.

29. Brunder, W., Khan, A.S., Hacker, J., and Karch, H. 2001. Novel type of fimbriae encoded by the large plasmid of sorbitol-fermenting enterohemorrhagic Escherichia coli O157:H(-). Infect. Immun. 69:4447-4457

30. Torres, A.G., et al. 2002. Identification and characterization of lpfABCC'DE, a fimbrial operon of enterohemorrhagic Escherichia coli O157:H7. Infect. Immun. 70:5416-5427.

31. Kim, S.H., and Kim, Y.H. 2004. Escherichia coli O157: $\mathrm{H} 7$ adherence to HEp-2 cells is implicated with curli expression and outer membrane integrity. J. Vet. Sci. 5:119-124.

32. Low, A.S., et al. 2006. Cloning, expression, and characterization of fimbrial operon $\mathrm{F} 9$ from enterohemorrhagic Escherichia coli O157:H7. Infect. Immun. 74:2233-2244.

33. Srimanote, P., Paton, A.W., and Paton, J.C. 2002.
Characterization of a novel type IV pilus locus encoded on the large plasmid of locus of enterocyte effacement-negative Shiga-toxigenic Escherichia coli strains that are virulent for humans. Infect. Immun. 70:3094-3100.

34. Jordan, D.M., et al. 2004. Long polar fimbriae contribute to colonization by Escherichia coli $\mathrm{O} 157: \mathrm{H7}$ in vivo. Infect. Immun. 72:6168-6171.

35. Rendon, M.A., et al. 2007. Commensal and pathogenic Escherichia coli use a common pilus adherence factor for epithelial cell colonization. Proc. Natl. Acad. Sci. U. S. A. 104:10637-10642.

36. Craig, L., Pique, M.E., and Tainer, J.A. 2004. Type IV pilus structure and bacterial pathogenicity. Nat. Rev. Microbiol. 2:363-378.

37. Mattick,J.S. 2002. Type IV pili and twitching motility. Annu. Rev. Microbiol. 56:289-314.

38. Winther-Larsen, H.C., et al. 2001. Neisseria gonorrhoeae PilV, a type IV pilus-associated protein essential to human epithelial cell adherence. Proc. Natl. Acad. Sci. U. S. A. 98:15276-15281.

39. Giron, J.A., Ho, A.S., and Schoolnik, G.K. 1991. An inducible bundle-forming pilus of enteropathogenic Escherichia coli. Science. 254:710-713.

40. Taylor, R.K., Miller, V.L., Furlong, D.B., and Mekalanos, J.J. 1987. Use of phoA gene fusions to identify a pilus colonization factor coordinately regulated with cholera toxin. Proc. Natl. Acad. Sci. U. S. A. 84:2833-2837.

41. Paranjpye, R.N., and Strom, M.S. 2005. A Vibrio vulnificus type IV pilin contributes to biofilm formation, adherence to epithelial cells, and virulence. Infect. Immun. 73:1411-1422.

42. Guinee, P.A., Jansen, W.H., and Agterberg, C.M. 1976. Detection of the K99 antigen by means of agglutination and immunoelectrophoresis in Escherichia coli isolates from calves and its correlation with entertoxigenicity. Infect. Immun. 13:1369-1377.

43. Giron, J.A., Levine, M.M., and Kaper, J.B. 1994. Longus: a long pilus ultrastructure produced by human enterotoxigenic Escherichia coli. Mol. Microbiol. 12:71-82.

44. Gismero-Ordonez, J., Dall'Agnol, M., Trabulsi, L.R., and Giron, J.A. 2002. Expression of the bundleforming pilus by enteropathogenic Escherichia coli strains of heterologous serotypes. J. Clin. Microbiol. 40:2291-2296.

45. de Oliveira-Garcia, D., et al. 2002. Characterization of flagella produced by clinical strains of Stenotrophomonas maltophilia. Emerg. Infect. Dis. 8:918-923.

46. Blattner, F.R., et al. 1997. The complete genome sequence of Escherichia coli K-12. Science. 277:1453-1474.

47. Francetic, O., Lory, S., and Pugsley, A.P. 1998. A second prepilin peptidase gene in Escherichia coli K-12. Mol. Microbiol. 27:763-775.

48. Strom, M.S., and Lory, S. 1993. Structure-function and biogenesis of the type IV pili. Annu. Rev. Microbiol. 47:565-596.

49. Sauvonnet, N., Gounon, P., and Pugsley, A.P. 2000. PpdD type IV pilin of Escherichia coli K-12 can be assembled into pili in Pseudomonas aeruginosa. J. Bacteriol. 182:848-854.

50. Sundin, C., Wolfgang, M.C., Lory, S., Forsberg, A. and Frithz-Lindsten, E. 2002. Type IV pili are not 
specifically required for contact dependent translocation of exoenzymes by Pseudomonas aeruginosa. Microb. Pathog. 33:265-277.

51. Nougayrede, J.P., and Donnenberg, M.S. 2004 Enteropathogenic Escherichia coli $\mathrm{EspF}$ is targeted to mitochondria and is required to initiate the mitochondrial death pathway. Cell Microbiol. 6:1097-1111.

52. Hicks, S., Frankel, G., Kaper, J.B., Dougan, G., and Phillips, A.D. 1998. Role of intimin and bundleforming pili in enteropathogenic Escherichia coli adhesion to pediatric intestinal tissue in vitro. Infect. Immun. 66:1570-1578.

53. Puente, J.L., Bieber, D., Ramer, S.W., Murray, W., and Schoolnik, G.K. 1996. The bundle-forming pili of enteropathogenic Escherichia coli: transcriptional regulation by environmental signals. Mol. Microbiol. 20:87-100.

54. Edwards, R.A., and Puente, J.L. 1998. Fimbrial expression in enteric bacteria: a critical step in intes- tinal pathogenesis. Trends Microbiol. 6:282-287.

55. Sauvonnet, N., Vignon, G., Pugsley, A.P., and Gounon, P. 2000. Pilus formation and protein secretion by the same machinery in Escherichia coli. EMBOJ. 19:2221-2228.

56. Datsenko, K.A., and Wanner, B.L. 2000. One-step inactivation of chromosomal genes in Escherichia coli K-12 using PCR products. Proc. Natl. Acad. Sci. U. S. A. 97:6640-6645

57. Sambrook, J., and Russell, D.W. 2001. Molecular cloning: a laboratory manual. Cold Spring Harbor Laboratory Press. Cold Spring Harbor, New York, USA. 854 pp.

58. Giron, J.A., Torres, A.G., Freer, E., and Kaper, J.B. 2002. The flagella of enteropathogenic Escherichia coli mediate adherence to epithelial cells. Mol. Microbiol. 44:361-379.

59. Parissi-Crivelli, A., Parissi-Crivelli, J.M., and Giron, J.A. 2000. Recognition of enteropathogenic Escherichia coli virulence determinants by human colostrum and serum antibodies. J. Clin. Microbiol. 38:2696-2700.

60. Laemmli, U.K. 1970. Cleavage of structural proteins during the assembly of the head of bacteriophage T4. Nature. 227:680-685.

61. Giron, J.A., Ho, A.S., and Schoolnik, G.K. 1993. Characterization of fimbriae produced by enteropathogenic Escherichia coli.J. Bacteriol. 175:7391-7403.

62. Jarvis, K.G., and Kaper, J.B. 1996. Secretion of extracellular proteins by enterohemorrhagic Escherichia coli via a putative type III secretion system. Infect. Immun. 64:4826-4829.

63. Tzipori, S., et al. 1987. Role of a 60-megadalton plasmid and Shiga-like toxins in the pathogenesis of infection caused by enterohemorrhagic Escherichia coli O157:H7 in gnotobiotic piglets. Infect. Immun. 55:3117-3125.

64. Roulland-Dussoix, D., and Boyer, H.W. 1969. The Escherichia coli B restriction endonuclease. Biochim. Biophys. Acta. 195:219-229. 